\title{
Effect of Glass Fiber Hybridization on the Behavior Under Impact of Woven Carbon Fiber/Epoxy Laminates
}

\author{
A. ENFedaque, ${ }^{1}$ J. M. Molina-Aldareguía, ${ }^{2}$ F. GÁlvez, ${ }^{1}$ \\ C. GONZÁLEZ ${ }^{1,2}$ AND J. LLORCA ${ }^{1,2}$ \\ ${ }^{I}$ Departamento de Ciencia de Materiales, Universidad Politécnica \\ de Madrid E. T. S. de Ingenieros de Caminos, 28040-Madrid, Spain \\ 'Instituto Madrileno de Estudios Avanzados de Materiales \\ (IMDEA Materiales) Cl Profesor Aranguren s/n, 28040-Madrid, Spain
}

\begin{abstract}
The low-velocity impact behavior was studied in hybrid laminates manufactured by RTM with woven carbon and glass (S2) fabrics. Specimens with different thicknesses and glass fiber content (from 0 to 21 vol.\%) were tested with impact energies in the range $30-245 \mathrm{~J}$ and the resulting deformation and fracture micromechanisms were studied using X-ray microtomography. The results of these analyses, together with those of the impact tests (maximum load and energy absorbed). were used to elucidate the role played by glass fiber hybridization on the fracture micromechanisms and on the overall laminate performance under low-velocity impact.
\end{abstract}

KEY WORDS: impact behavior, hybrid composites, fracture micromechanisms, X-ray microtomography.

\section{INTRODUCTION}

$\mathbf{F}$ IBER-REINFORCED COMPOSITES MADE up of epoxy matrices reinforced with highstrength carbon fibers are becoming standard structural materials in many industrial applications which require very high specific stiffness and strength. They are normally used in the form of laminates obtained by stacking composite lamina (with either unidirectional or woven fiber reinforcement) with different fiber orientations to optimize the laminate properties as a function of the loading conditions. It is well known, however, that composite laminates are very susceptible to impact damage, which can significantly reduce their mechanical properties, and that they may behave in a brittle fashion under impact, penetration being attained with limited energy dissipation. The behavior of carbon/epoxy 
laminates under impact was and still is a very active research area and the progress of the state-of-the-art on this topic can be found in various reviews published over the last 20 years $[1-4]$.

A composite laminate subjected to low-velocity, out-of-plane impact is mainly loaded in bending, which induces shear stresses at the center of the laminate and compressive and tensile stresses on the top and bottom surfaces, respectively. The relative magnitude of these stresses is controlled by the geometry of the laminate plate (mainly the thickness-tospan ratio). Geometry, together with the lamina and interply strength, determine the onset of damage which, according to the experimental evidence, follows three main mechanisms [1-5]. Contact stresses between the impactor and the top lamina may induce failure by matrix crushing and matrix/interface decohesion and nucleate cracks perpendicular to the ply. These cracks propagate through the top ply and are deflected through the interface with the next ply, leading to an interply crack which extends considerably away from the impact point. The delamination crack is eventually deflected into the lower ply by matrix shear cracking due to the presence of large shear stresses radiating from the contact point in a conical fashion. This process can be repeated several times depending on the magnitude of the contact stresses, leading to a conical damage zone starting from the contact point formed by transverse matrix cracks and interply delaminations. Damage can also start at the bottom ply if the tensile stresses generated during bending are large enough to induce fiber and/or matrix fracture. These cracks propagate upward through the lamina until they are deflected at the interply interface and delamination progresses until it is deflected upward by matrix cracking. Finally, interply decohesion may develop even in the absence of visible damage in the top and bottom plies [6]. These delaminations reduce the stiffness of the laminate and lead to major reductions in the compressive strength because the laminate is subdivided into thinner sublaminates with lower buckling load.

Strategies to improve the impact behavior of composite laminates depend on the dominant damage mechanisms. For instance, improving the interface strength (through Z-pinning or insertion of tough polymer layers between plies) may be very useful in the case of low-energy impact which induces damage by delamination, but this does not guarantee better penetration resistance. Under high-energy impact conditions, the laminate behavior is given by the maximum load supported by the laminate and the total energy dissipated, and these parameters depend not only on the mechanisms of damage initiation but also on the propagation of damage through the layered structure. Thus, the behavior under impact (maximum load-bearing capacity and energy absorbed during impact) of composite laminates depends on many factors, and many studies were devoted to studying the influence of different parameters (laminate thickness [7,8], preform architecture [8,9], laminate lay-up [10,11], etc.). While these investigations indicate that impact performance can be improved using thicker laminates or that weave-fabric composites offer better impact resistance than unidirectional ones, one efficient way to improve the impact behavior of carbon/epoxy laminates is by means of hybridization with high strainto-failure fibers $[12,13]$. In particular, glass fibers are the best option from the viewpoint of cost, availability, and ease of processing, and hybrid carbon-glass fiber composites have consistently demonstrated better damage tolerance under impact than their carbon-fiber counterparts [13-17].

Hybridization of carbon/epoxy laminates with glass fibers may have negative effects on stiffness and strength due to the inferior properties of glass fibers. Hence, it is important to optimize the laminate so that impact resistance is increased with a minimum penalty on other mechanical properties. This task requires a detailed understanding of the effect of 
glass fibers on the deformation and damage mechanisms under impact. This information is not found, however, in the open literature, in which the superior impact performance of hybrid composites is always attributed to the higher strain-to-failure of glass fibers, without analyzing the changes in the energy-dissipation micromechanisms. This is precisely the objective of this investigation, in which hybrid laminates manufactured by RTM with woven carbon and glass (S2) fabrics were subjected to low-velocity impact using a dropweight apparatus. Specimens with different thicknesses and lay-up configurations were tested using various impact energies and the resulting deformation and fracture micromechanisms were studied using X-ray microtomography. The results of these analyses, together with those of the impact tests (maximum load and energy absorbed), were used to elucidate the role played by glass fiber hybridization, on the mechanical behavior, under impact of composite laminates.

\section{MATERIALS AND EXPERIMENTAL TECHNIQUES}

Composite laminates were manufactured by resin-transfer molding from RTM6 epoxy resin and woven carbon and glass fiber fabrics purchased from Hexcel. Carbon fabric (reference G0926) was made up of high-strength fibers with a five-harness satin architecture, while glass fabric (reference 6781) was made up of $\mathrm{S} 2$ glass fibers with an eight-harness satin structure. Both fabrics were balanced in the weft and warp orientations. Composite panels were consolidated and cured in vacuum at $180^{\circ} \mathrm{C}$ for $2 \mathrm{~h}$. Six different laminates were manufactured and their denomination, nominal thickness, stacking sequence, and nominal proportion of carbon and S2 glass fibers are presented in Table 1. The denomination includes the number of plies and, in the case of hybrid materials, the nominal proportion in volume of $\mathrm{S} 2$ glass fiber fabrics in the laminate. Two laminates with different thicknesses $(5.7$ and $7.3 \mathrm{~mm}$ ) only contained $\mathrm{C}$ fibers while four hybrid laminates were manufactured with two thicknesses and proportions of glass fibers (either around $20 \%$ or $11-12 \%$ ). Plates were inspected by ultrasounds after manufacturing and were free of defects. The actual thickness $t$ of each laminate was determined as the average of eight measurements carried out with a micrometer (resolution $\pm 0.01 \mathrm{~mm}$ ). Areal density $(\rho t)$ was computed from the plate dimensions and the mass, the latter, measured with a balance with a resolution of $\pm 0.01 \mathrm{~g}$.

Square specimens of $145 \times 145 \mathrm{~mm}^{2}$ were cut from the composite panels. Low-velocity impact tests were carried out using a DynaTup 8250 drop-weight testing machine. The composite plates were simply supported by the fixture at the edges with special

Table 1. Denomination, nominal thickness, stacking sequence, and proportion of carbon and \$2 glass fibers in laminates.

\begin{tabular}{lclcc}
\hline Laminate & $\begin{array}{c}\text { Thickness } \\
(\mathbf{m m})\end{array}$ & \multicolumn{1}{c}{ Stacking sequence } & C (vol.\%) & S2 (vol.\%) \\
\hline C-16 & 5.7 & {$\left[(45 / 0)_{4}\right]_{\mathrm{s}}$} & 100 & 0 \\
$\mathrm{C}-20$ & 7.3 & {$\left[(45 / 0)_{4}\right]_{\mathrm{s}}$} & 100 & 0 \\
$\mathrm{H}-18(21)$ & 5.5 & {$\left[45 / 45^{\mathrm{s}} / 0 / 45^{\mathrm{s}} / 0 / 45^{\mathrm{s}} / 0 / 45^{\mathrm{s}} / 45\right]_{\mathrm{s}}$} & 79 & 21 \\
$\mathrm{H}-20(19)$ & 6.3 & {$\left[45 / 45^{\mathrm{s}} / 0 / 0 / 45^{\mathrm{s}} / 45 / 0 / 45 / 45^{\mathrm{s}} / 45\right]_{\mathrm{s}}$} & 81 & 19 \\
$\mathrm{H}-20(12)$ & 6.6 & {$\left[45 / 45^{\mathrm{s}} / 0_{2} / 45 / 0 / 45^{\mathrm{s}} / 0 / 45_{2}\right]_{\mathrm{s}}$} & 88 & 12 \\
$\mathrm{H}-22(11)$ & 7.2 & {$\left[45 / 45^{\mathrm{s}} / 0 / 45 / 0 / 45 / 0 / 45^{\mathrm{s}} / 0 / 45_{2}\right] \mathrm{s}$} & 89 & 11 \\
\hline
\end{tabular}


clamping tweezers and an impact-free area of $127 \times 127 \mathrm{~mm}^{2}$. The specimens were impacted at the center using a $12.7 \mathrm{~mm}$ diameter steel tup. Incident impact energies in the range $30-245 \mathrm{~J}$ were chosen by selecting the weight and the initial position of the impactor to obtain fully penetrated and not penetrated specimens. Nevertheless, the impact velocity for all the tests reported here was in the range $3.2-4.0 \mathrm{~m} / \mathrm{s}$. The impactor was instrumented with a $50 \mathrm{kN}$ load cell and an accelerometer to continuously measure and record the applied force, $P$, and the tup displacement, $\delta$, and velocity.

$\mathrm{X}$-ray microtomography measurements were performed using a Phoenix Nanotom ${ }^{\mathrm{B}}$ equipment. The system is equipped with a high-power nanofocus $\mathrm{X}$-ray tube offering $0.3 \mu \mathrm{m}$ detail detectability and a high tension of $160 \mathrm{kV}$ and a 12 -bit $2300 \times 2300$ pixel charge-coupled device (CCD) detector. Data were collected at $80 \mathrm{kV}$ and $120 \mathrm{~mA}$ with a voxel size of $36.38 \mu \mathrm{m}$. For tomographical reconstruction, transmission X-ray images were acquired from 900 rotation views $\left(0.4^{\circ}\right.$ step rotation). Reconstruction was performed using the Phoenix Datos $\mid X$ Software package. In some measurements, a dye penetrant was used as a contrasting agent. The dye was a mixture of isopropyl alcohol, zinc iodide, Kodak photo solution, and distilled water [18].

\section{EXPERIMENTAL RESULTS}

Between four and six impact tests were carried out on each type of laminate. Impact energies were selected in such a way that full penetration was achieved in at least three specimens of each laminate. In addition, the impact energy was selected in several tests; therefore, the tup was stopped after reaching the maximum load to determine the fractions of the total kinetic energy dissipated by damage and stored as elastic energy at this point. Load-displacement $(P-\delta)$ curves corresponding to full penetration tests in the C-16 laminate are plotted in Figure 1(a). The energy dissipated was computed as the area within the load-displacement curve. The different tests showed consistent results. The mechanical response was fairly linear up to the maximum load $(\approx 11-12 \mathrm{kN}){ }^{* *}$ which was attained when the tup displacement had reached $5 \mathrm{~mm}$ and the laminate had undergone extensive damage. After the maximum, the load carried by the composite decreased rapidly while extensive damage developed under the tup. The final part of the $P-\delta$ curve showed a marked change in curvature (marked with an arrow in Figure 1(a)), which stands for the instant at which full penetration was achieved. The residual load carried by the tup after this point corresponds to friction of the lateral tup surfaces with the laminate, as the laminate is completely perforated (Figure 1(b)).

The corresponding load-displacement curves for the full penetration impact tests of the H-18(21) laminate are plotted in Figure 1(c). The experimental scatter was very limited, once again. The curves presented the same features observed for the carbon-epoxy laminates, indicating that the deformation and damage mechanisms are equivalent. However, the maximum load and, particularly, the tup displacement at maximum load and at full penetration were consistently higher in the hybrid materials, although the H-18(21) laminate was slightly thinner than the C-16 plate $(5.5 \mathrm{~mm}$ vs. $5.7 \mathrm{~mm})$.

The energy absorbed by the laminates upon impact is given by the area under the $P-\delta$ curves in the test with full penetration and is plotted as a function of the tup displacement in Figure 2 for the C-16 and $\mathbf{H}-18(21)$ laminates. The curves are stopped at full penetration

\footnotetext{
**The ripples in the load-displacement curves are due to the reflection of the stress waves.
} 


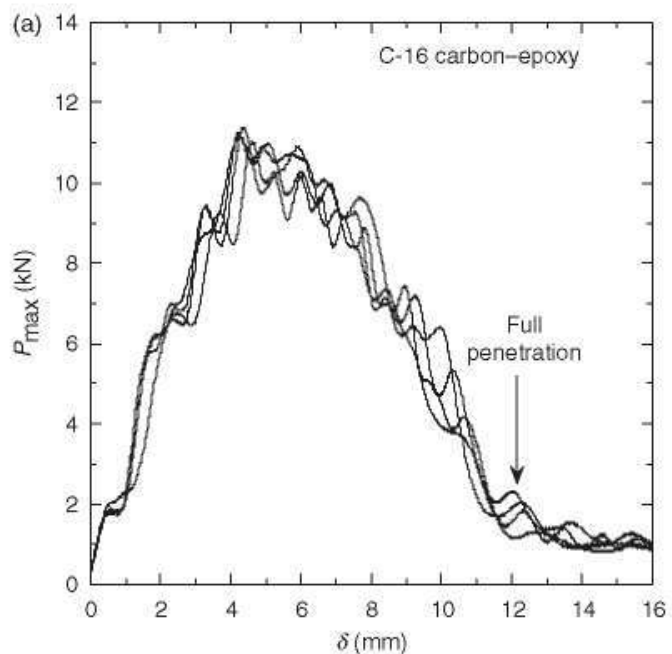

(b)
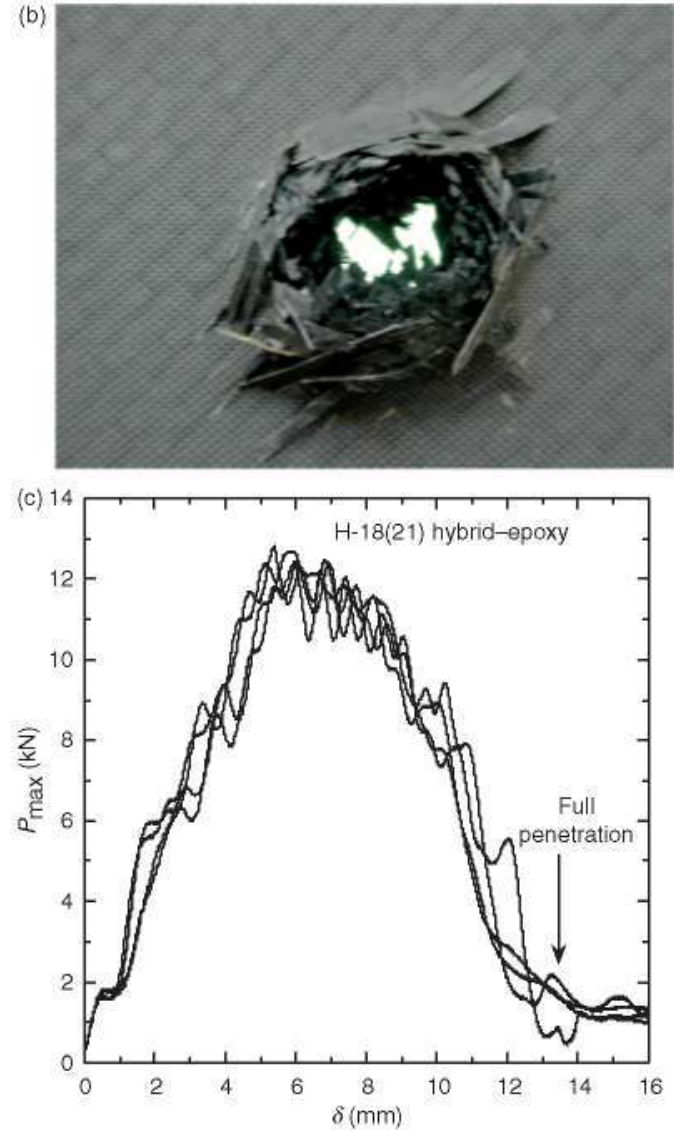

Figure 1. Load-displacement ( $P$ - $\delta$ ) curves of laminates subjected to out-of-plane low-velocity impact: (a) C16 carbon-epoxy laminate with $5.7 \mathrm{~mm}$ nominal thickness. The arrows indicate the point of full penetration; (b) optical micrograph of the bottom layer a C-16 carbon-epoxy laminate after an impact test with full penetration; and (c) $\mathrm{H}-18$ (21) hybrid carbon/S2 glass-epoxy laminate with $5.5 \mathrm{~mm}$ nominal thickness. The arrows indicate the point of full penetration. 
because further energy dissipation was due to friction between the tup and the perforated sample. The curves for both materials showed a sigmoidal shape, which accounts for the two main deformation mechanisms: the elastic deformation of the plate and the nonlinear deformation associated with the damage processes. The former is dominant at the beginning of the impact whereas fracture and damage control post-peak behavior. This hypothesis is supported by the results of tests with lower energy, in which the tup did

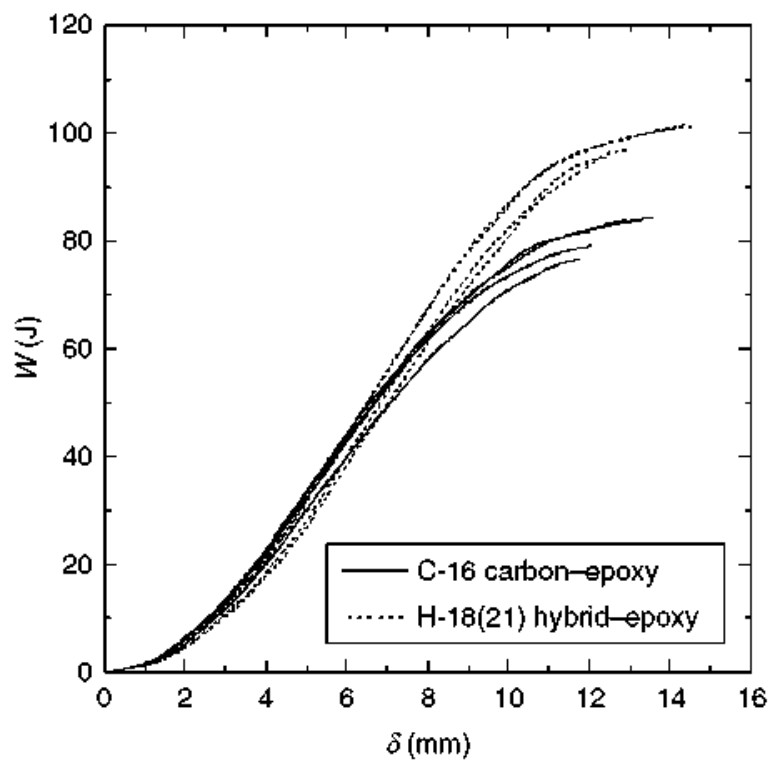

Figure 2. Energy-displacement (W-8) curves of $C-16$ and H-18(21) laminates subjected to out-of-plane lowvelocity impact.

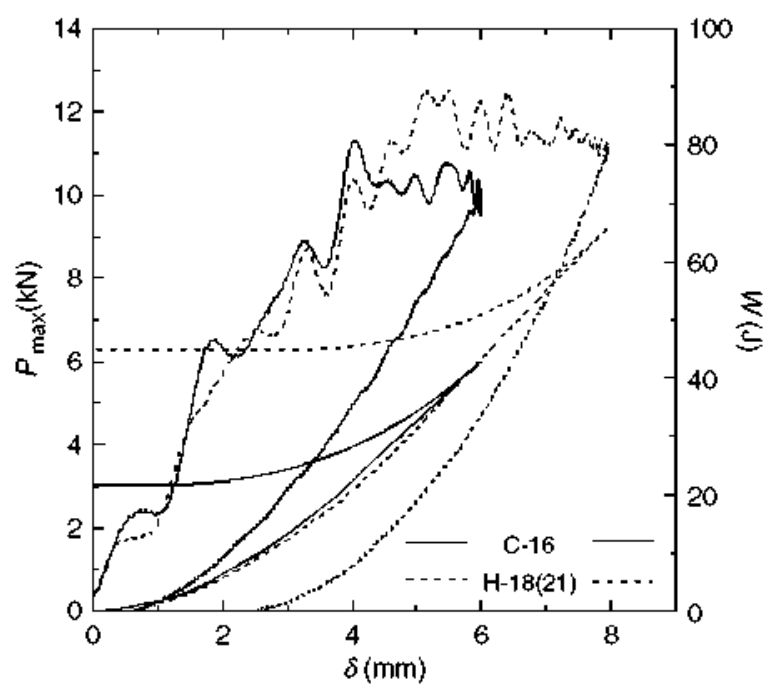

Figure 3. Load-displacement ( $P-\delta$ ) and energy-displacement $(W-\delta)$ curves corresponding to $C-16$ and H-18 (21) specimens impacted with 42 and $63 \mathrm{~J}$, respectively, in which full penelration was not achieved. 
not penetrate the laminate but rebounded. The corresponding $P-\delta$ and $W-\delta$ curves are plotted in Figure 3 for two representative tests on the C-16 and H-18(21) laminates. The maximum displacement of the tup was $\approx 6-7 \mathrm{~mm}$ and the rebound of the tup started just beyond the peak load. The $W-\delta$ curves showed that between $30 \%$ and $50 \%$ of the energy absorbed by the laminate at this point was elastic and was returned to the tup during rebound, while the remaining energy was dissipated. The behavior of the carbon and hybrid laminates is also consistent with this picture. The energy absorbed by the carbon laminates was slightly higher than that of the hybrid laminates in the elastic region due to their greater stiffness (Figure 2). Nevertheless, hybrid laminates dissipated much more energy during fracture and the total energy dissipated by the hybrid laminates during impact was higher.

Similar curves were obtained for all the other materials, and the main results of the impact tests are summarized in Figures 4 and 5. They show, respectively, the maximum load, $P_{\max }$ and the energy dissipated during impact, $W$, as function of the laminate thickness $t$ for all the materials. These figures demonstrate that thicker laminates carried higher loads and absorbed more energy during impact and that hybrid laminates performed better than carbon laminates. Thus, the hybridization with $\mathbf{2} 2$ glass was clearly beneficial from the viewpoint of impact behavior. In addition, the results in Figure 4 are useful for understanding the dominant failure mode. Depending on the stiffness of the laminate panel, failure by out-of-plane impact may be due to two mechanisms. If the plate is extremely rigid, fracture has to occur by formation of a cylindrical plug under the tup and the load-bearing capability of the plate depends on the out-of-plane shear strength of the laminate and is proportional to the thickness $t$. Conversely, if the laminate plate is very flexible, the maximum load supported by the composite is controlled by the tensile fracture of the bottom ply due to the bending stresses. In this case, $P_{\max }$ depends on the ply tensile strength and is proportional to $t^{2}$. The variation of $P_{\max } / t$ and $P_{\max } / t^{2}$ with the laminate thickness is plotted for all the materials in Figure 4(a) and (b), respectively. These curves show that $P_{\text {max }} / t$ increases with the laminate thickness in all the materials and precludes fracture by the formation of a cylindrical plug. The curves in Figure $4(\mathrm{~b})$ show that $P_{\max } / t^{2}$ was constant (within the experimental scatter) for all the laminates and these results seem to indicate that fracture of the bottom ply was the mechanism controlling the maximum load upon impact. In addition, the results in Figure 5 show that the energy dissipated during impact was approximately proportional to the square of the laminate thickness for each material. This behavior is compatible with the development of conical damage behind the tup, as was postulated in previous investigations [1-3], whose volume is proportional to $t^{2}$.

The presence of glass fibers in the laminate not only improved the impact behavior (in terms of maximum load and energy dissipated), but also increased the laminate density. It is important to demonstrate for weight-critical applications whether these benefits are maintained when the laminates are compared on the basis of areal density, $\rho t$, instead of laminate thickness. The corresponding values of the maximum load and the energy absorbed, divided by the laminate areal density $\rho t$, are plotted as a function of the laminate thickness in Figure 6(a) and (b), respectively. They show that hybridization with S2 glass fibers improves the maximum load-carrying capability and the energy dissipated by the laminate for a given value of the laminate areal density. It should be noticed, nevertheless, that the improvement in energy dissipated is significantly higher.

Finally, results were presented for two sets of laminates containing 11-12 and $\approx 20 \mathrm{vol} . \%$ of S2 glass fiber plies. Although all the laminates had different thicknesses, and it was not possible to make direct comparisons; it may be concluded from Figures 4 

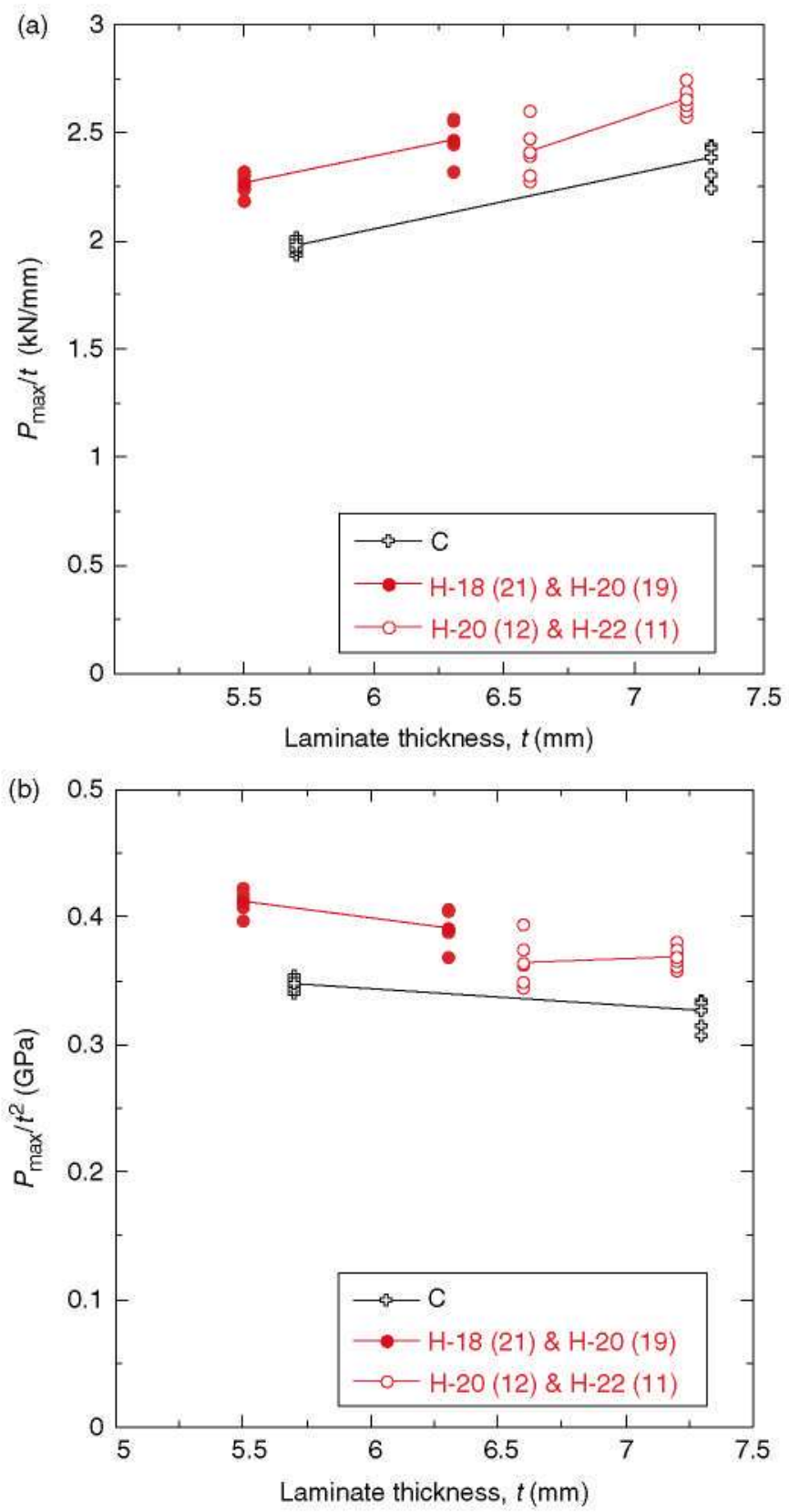

Figure 4. Maximum load supported by the laminates subjected to out-of-plane low-velocity impact as a function of the laminate thickness, $t$ : (a) $P_{\max } / t$ and (b) $P_{\max } / t^{2}$.

and 5 that laminates with $20 \mathrm{vol} . \%$ of S2 glass fibers performed slightly better than those with only $11-12 \%$. These differences disappeared when the laminates were compared in terms of the areal density, as is shown in Figure 6. Thus, increasing the glass fiber content does not monotonously improve the impact performance of hybrid composites in terms of specific properties (impact strength/weight and energy dissipated/weight). 


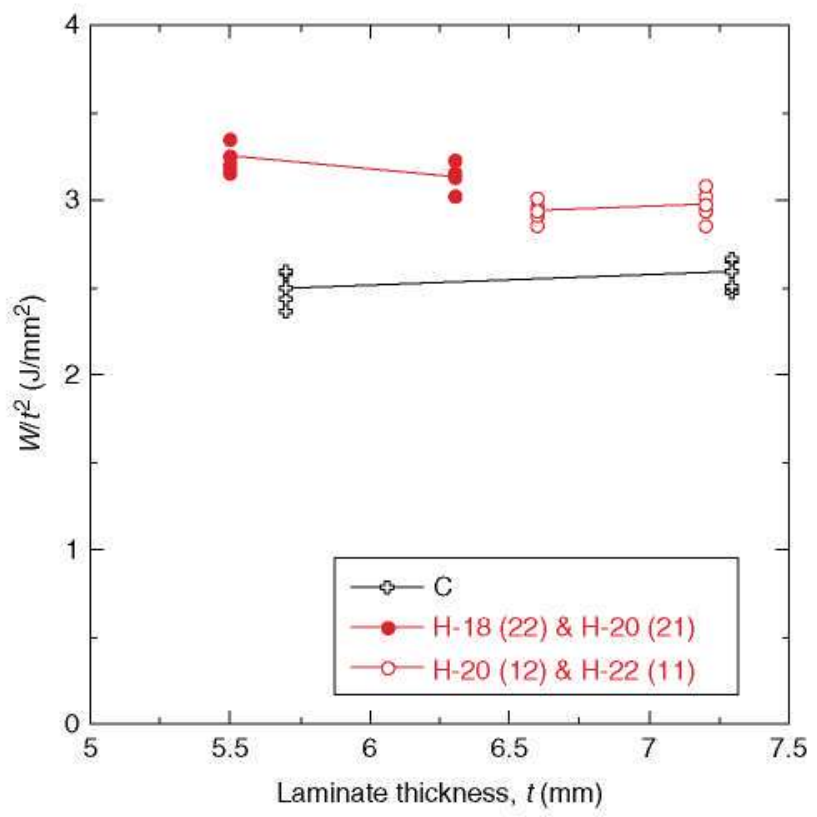

Figure 5. Energy dissipated, W, normalized by $\mathrm{e}^{2}$, under low-velocity, out-of-plane impact as a function of the laminate thickness.

\section{FRACTURE MICROMECHANISMS}

Damage assessment in composites laminates subjected to impact can be carried out using destructive and nondestructive techniques [19]. Destructive methods (de-ply technique and serial sectioning fractography) provide a very detailed characterization of the damage pattern but specimen preparation is extremely time consuming and there are always doubts regarding damage introduced during specimen preparation. Therefore, nondestructive techniques (such as ultrasounds and radiography) are preferred. Ultrasonic measurements are particularly suitable for detecting the location and extent of interply delaminations, but they are not very sensitive to matrix cracks or fiber breakages. Conversely, radiography is very useful for detecting matrix cracks but detection of interply delaminations is difficult because they are very thin and there is little difference between the absorption coefficient of epoxy, carbon fibers, and air. Contrast enhancement can be obtained by infiltrating a liquid with a high X-ray absorption coefficient (e.g., ZnI), leading to excellent characterizations of damage by matrix cracking and interply delamination in flat specimens subjected to in-plane damage [20]. However, conventional transmission radiography does not provide information about the depth of the defects and it is not suitable for characterizing damage due to impact, which is fully three dimensional.

Full three-dimensional characterization of interply and intraply damage can be obtained through the use of X-ray-computed microtomography, which provides an actual three-dimensional reconstruction of the damaged microstructure from a number of $\mathrm{X}$-ray radiographies obtained at different angles. The potential of this technique for studying damage in carbon-epoxy composites has already been demonstrated [21-23] and it is used here to study the effect of glass fiber hybridization on the deformation and fracture micromechanisms of carbon-epoxy laminates. 

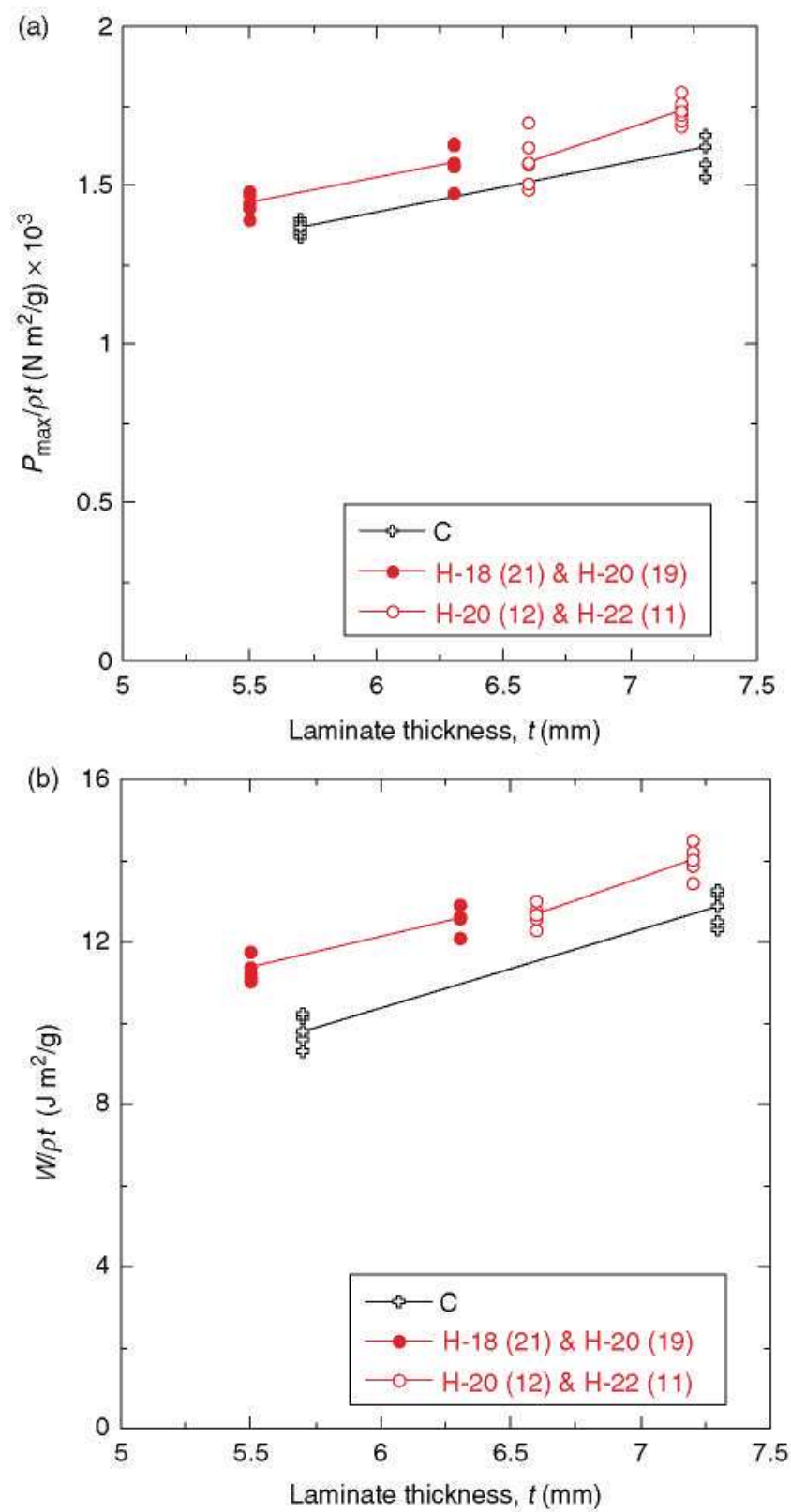

Figure 6. (a) Maximum load, normalized by the areal density $\rho t$, as a function of the laminate thickness, $t$; and (b) energy dissipated, normalized by the areal density pt, as a function of the laminate thickness, $t$.

Specimens, which underwent full penetration, showed extensive damage and it was very difficult to determine the sequence of fracture events. Therefore, analysis by X-ray microtomography focused on specimens which did not undergo full penetration. Sections perpendicular to the plies of the C-16 laminate with a thickness of $5.7 \mathrm{~mm}$ impacted with $63 \mathrm{~J}$ are shown in Figure 7. They were obtained at various distances from the impact axis, and provided very useful information about the fracture processes when the laminate was 
(a)

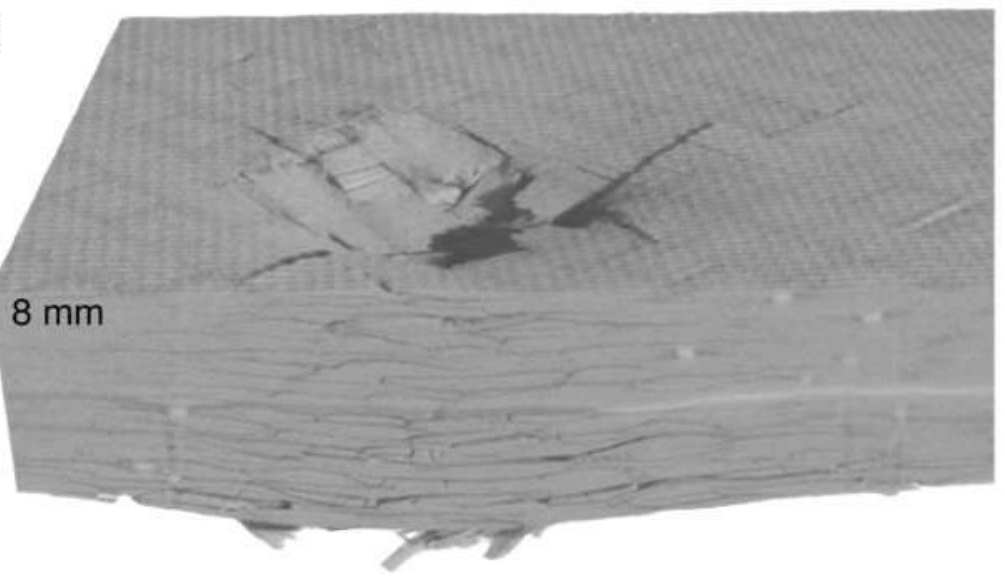

(b)

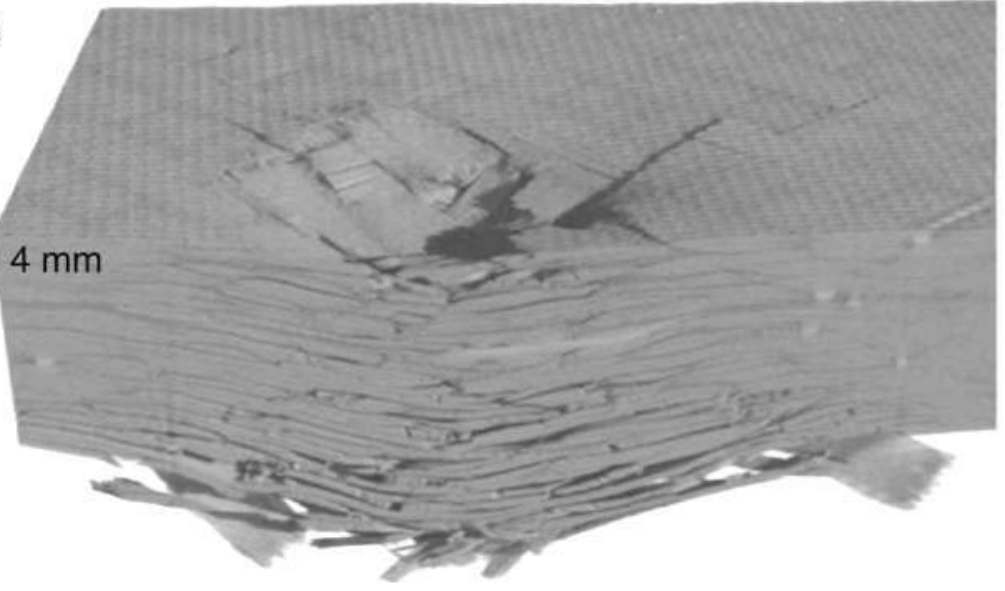

(c)

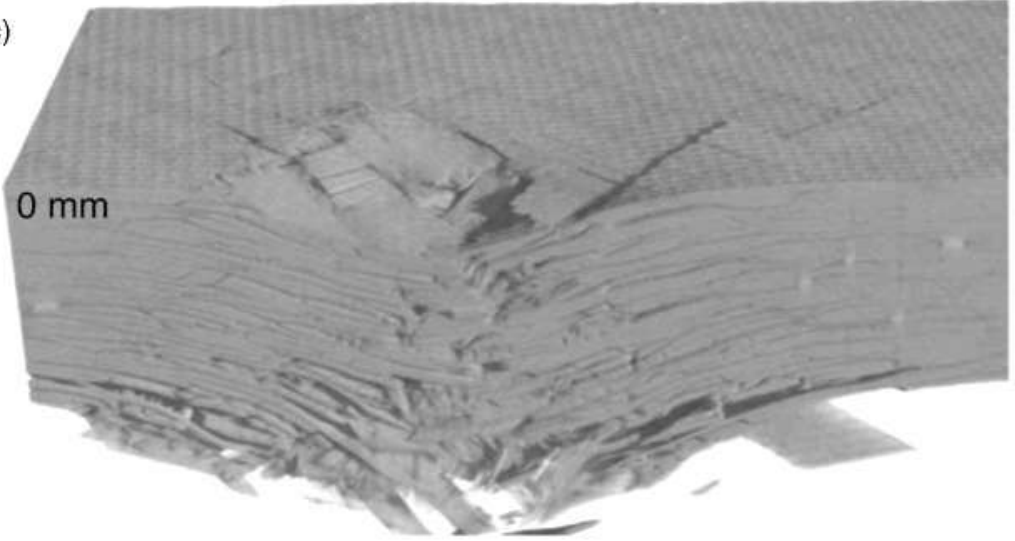

Figure 7. X-ray tomography sections of a C-16 composite laminate subjected to out-of-plane low-velocity impact with 63 J: (a) $8 \mathrm{~mm}$ from the impact axis; (b) $4 \mathrm{~mm}$ from the impact axis; and (c) under the impact axis. The laminate thickness was $5.7 \mathrm{~mm}$. 
subjected to different deformation levels. Further away (i.e., $8 \mathrm{~mm}$ ) from the impact axis, damage was observed in the form of tensile fracture of the bottom plies (Figure 7(a)). Intraply cracks formed at the bottom plies, propagated through the lamina until they were deflected at the interply interface and delamination progressed until interply cracks were deflected by matrix cracking into upper plies. This process was visible throughout the whole section although the damaged zone was larger near the bottom plies. The laminate section at $4 \mathrm{~mm}$ from the impact axis (Figure 7(b)) showed extensive damage near the bottom plies by delamination and intraply fracture because the stiff carbon plies were not able to withstand the large strains induced by the impact of the hemispherical tup. In addition, failure by crushing was seen in the top plies. The intraply cracks generated by crushing were deflected at the interfaces and led to the development of the interface cracks between the upper plies observed in Figure 7(a). Damage was, however, more localized near the top plies and the overall damaged zone presented a conical shape. The section located just below the impactor (Figure 7(c)) showed the formation of an incipient crack through the laminate thickness formed by the coalescence of the interply cracks created in the bottom and top plies. The conical shape of the damaged region was also evident in the section.

The effect of glass fiber hybridization is readily observed when Figure 7 is compared with the sections shown in Figure 8, which correspond to the H-18 (21) laminate with a thickness of $5.5 \mathrm{~mm}$ impacted with $63 \mathrm{~J}$. The dominant damage processes were equivalent to those found in the carbon-epoxy laminates, namely tensile fracture of the bottom plies and crushing of the top plies under the tup. The intraply cracks in the bottom and top plies grew upwards and downwards, respectively, leading to the development of delamination cracks, and final fracture took place by the formation of a crack through the laminate thickness (Figure 8(c)). Comparison of Figures 7(c) and 8(c) demonstrates, however, that the amount of damage in the carbon-epoxy laminate was far higher than in the hybrid-epoxy composite for equivalent impact conditions. At $6 \mathrm{~mm}$ from the impact axis (Figure 8(a)), damage in the hybrid composite was limited to tensile facture of the bottom carbon ply and to delamination between carbon plies (marked with arrows in Figure 8(a)). The S2 glass plies were intact and impeded the propagation of interply cracks from the bottom ply toward the center of the laminate. The reason for this behavior is more obvious in Figure 8(b), which shows that the $\$ 2$ glass plies were able to accommodate the deformations imposed by the hemispherical impactor without fracture due to the higher strain-to-fracture of the glass fibers. Thus, damage was by intraply fracture and delamination was localized in the carbon plies, but the $\mathrm{S} 2$ glass plies were able to hold the laminate together. Fracture of the laminate only began when the $\mathbf{S} 2$ glass plies were finally broken by shear (Figure 8(c)). The higher strain-to-failure of the $\mathrm{S} 2$ glass plies thus helped to sustain higher deformations before laminate fracture by the percolation of a throughthickness crack and increased the maximum load-bearing capability of the composite. In addition, the $\mathbf{S} 2$ plies failed at higher strains than the carbon plies and absorbed more energy, significantly improving the energy dissipated under impact.

It should be noted that the higher deformability of the \$2 glass plies also inhibited the propagation of interface cracks. To quantify the differences more accurately, samples were immersed in a solution containing $\mathrm{ZnI}$ prior to X-ray microtomography. The extent of interply delamination near the bottom of the laminate between $\mathrm{C} / \mathrm{S} 2$ and $\mathrm{C} / \mathrm{C}$ plies is shown in Figure 9(a) and (b), respectively. These differences were not caused by changes in the interply toughness (which was mainly controlled by the epoxy properties) but they were also a consequence of the higher deformability of the S2 glass fiber plies. In the absence 
(a)
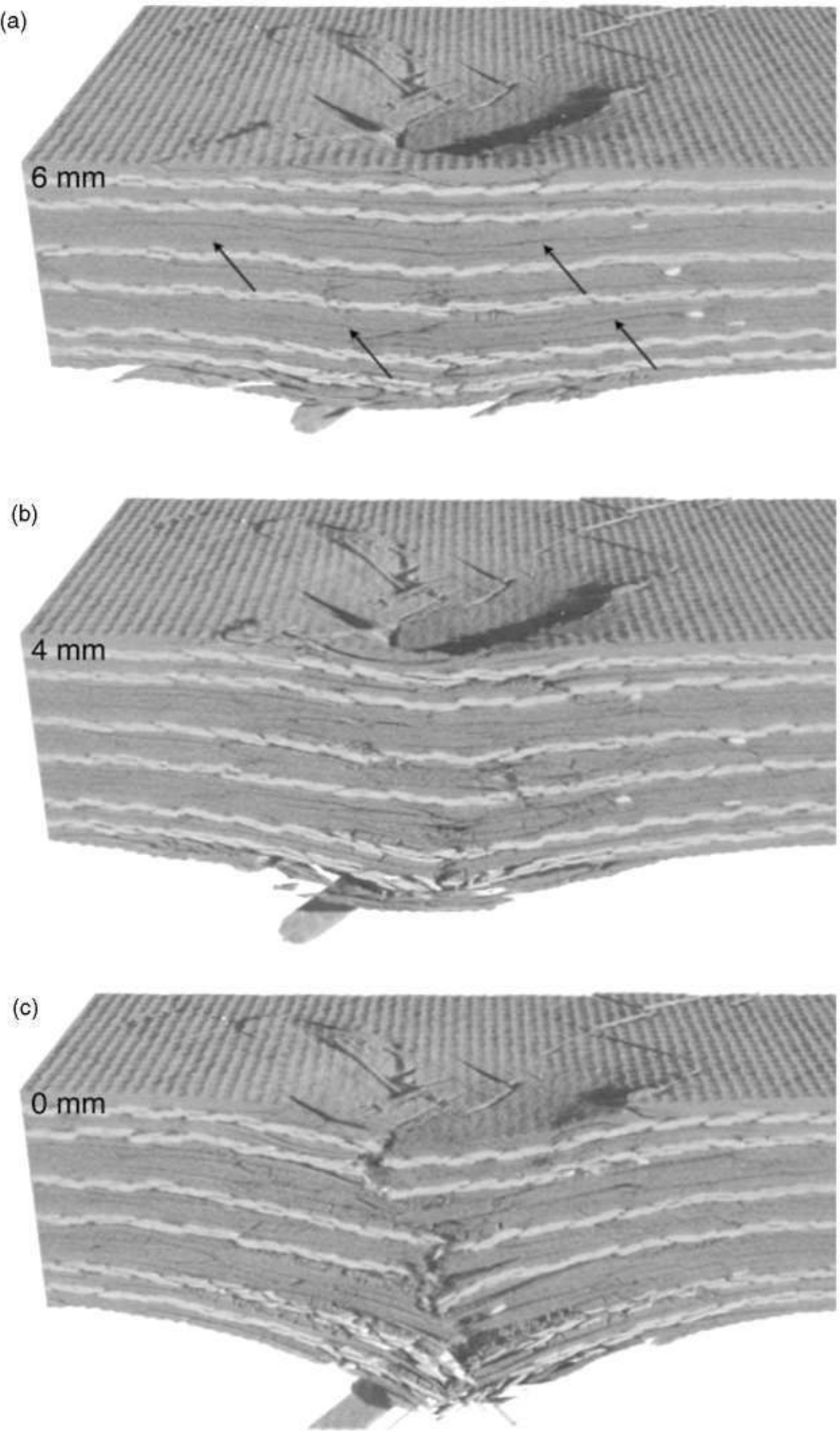

Figure 8. X-ray tomography sections of a H-18 (21) composite laminate subjected to out-of-plane low-velocity impact with $63 \mathrm{~J}$ : (a) $6 \mathrm{~mm}$ from the impact axis; (b) $4 \mathrm{~mm}$ from the impact axis; and (c) under the impact axis. The laminate thickness was $5.5 \mathrm{~mm}$. 
of cracking, delamination did not develop between C and S2 plies while intraply cracks in the $\mathrm{C}$ plies acted as stress concentrators which promoted delamination between $\mathrm{C}$ plies.

Extensive delamination between $\mathrm{C}$ plies did not enhance the overall energy dissipation and this is in agreement with recent numerical simulations [24], which found that the contribution of intraply failure to the total energy dissipated was far higher than that provided by interply delamination. In this respect, the location of the glass fiber plies (near to but not on the top and bottom laminate surface) helped to increase the laminate performance upon impact. The maximum load was controlled by the fracture of the carbon ply at the bottom though the intraply cracks did not propagate into the laminate but were stopped at the S2 glass ply, and a similar process occurred with cracks formed by crushing on the top ply (Figure 8(a)). In addition to stopping the intraply cracks, the glass fiber plies accommodated the impact deformation, and the inner carbon plies in the hybrid composite did not fail at low strains although they experienced extensive delaminations to accommodate the deformation of the glass fiber plies. This behavior is in contrast with the brittle behavior of the composites without glass fiber plies in which extensive ply cracking was observed away from the impact axis (Figure 7(a)).

Variations in the laminate thickness did not change the dominant deformation failure and micromechanisms, although the volume of the conical damage zone increased with $t^{2}$ (Figure 10) and the corresponding energy dissipated increased accordingly (Figure 5). Regarding the effect of the volume fraction of glass fibers in the laminate, they can be analyzed from the sections in Figure $8(21 \%$ of S2 glass fibers) and in Figure 11 ( $11 \%$ of S2 glass fibers). Although these sections correspond to two laminates with different thicknesses ( 5.5 and $7.2 \mathrm{~mm}$, respectively) impacted with different energies ( 63 and $92 \mathrm{~J}$, respectively), the damage state in both cases was comparable because both correspond to tests in which the tup was stopped right after attaining maximum load. The specimen with 11 vol. $\%$ of S2 glass fibers (Figure 11(a)) showed the beneficial effect of the two glass fiber plies near the top and bottom surfaces, which impeded the propagation into the laminate of the intraply cracks formed on the surfaces. Differences with the laminate reinforced with higher volume fraction of S2 glass fibers appeared in the inner carbon plies, which underwent damage by delamination and intraply cracking (Figure 11(b)). Carbon plies of laminates with a higher S2 glass fiber content subjected to similar deformation (Figure 8(b)) only showed damage by delamination, indicating that
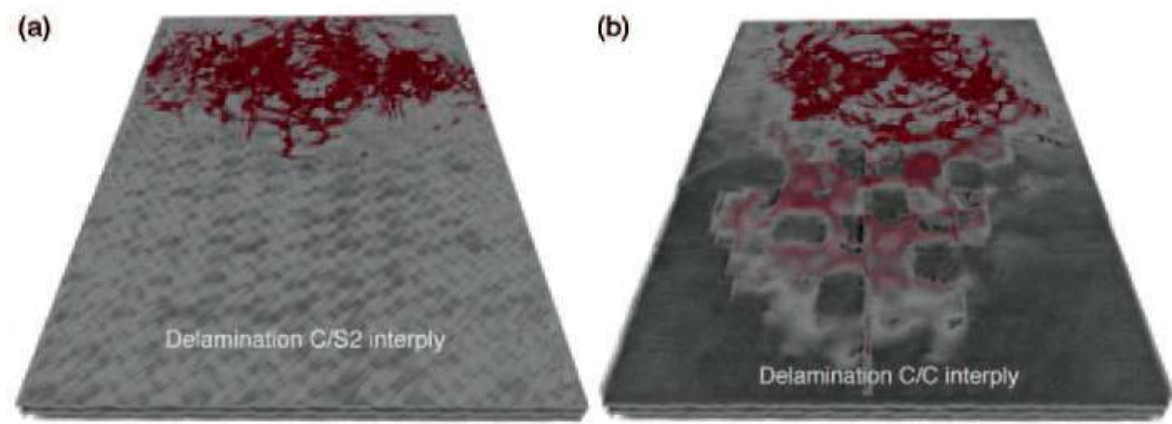

Figure 9. Delamination between plies located near the bottom of the H-18 (21) composite laminate subjected to out-of-plane low-velocity impact with $63 \mathrm{~J}$ : (a) delamination at C/S2 glass interply and (b) delamination at $\mathrm{C} / \mathrm{C}$ interply. Contrast was enhanced with a $\mathrm{Znl}$ solution and delaminated regions appeared in red. The laminate thickness was $5.5 \mathrm{~mm}$. 


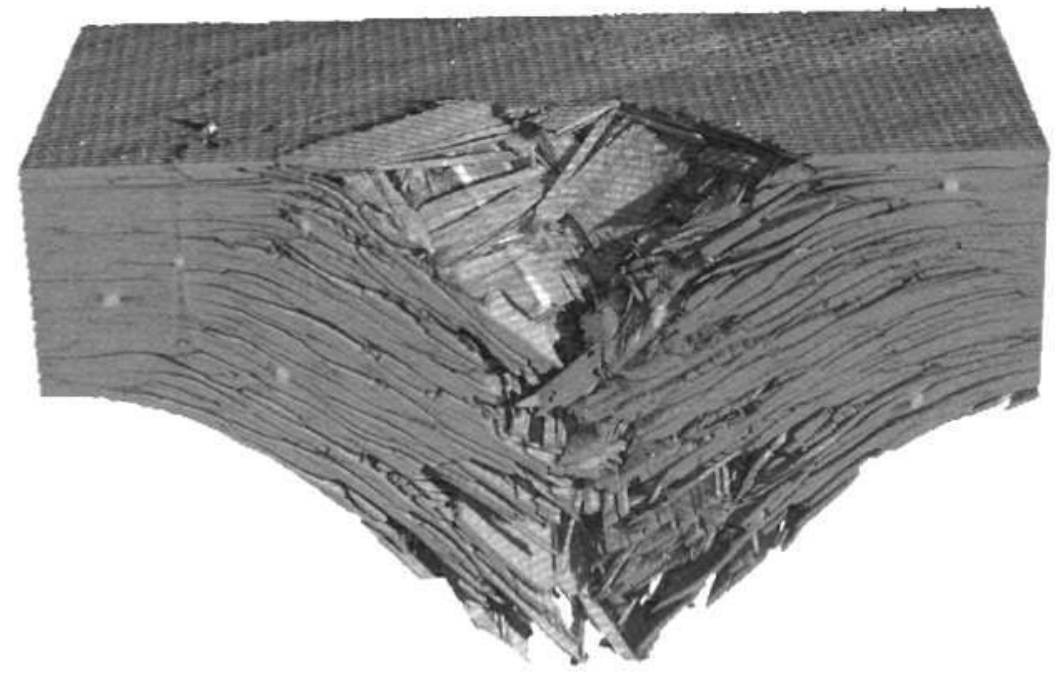

Figure 10. X-ray tomography sections of the C-20 carbon-epoxy laminate subjected to out-of-plane lowvelocity impact with $92 \mathrm{~J}$. The laminate thickness was $6.3 \mathrm{~mm}$.

(a)

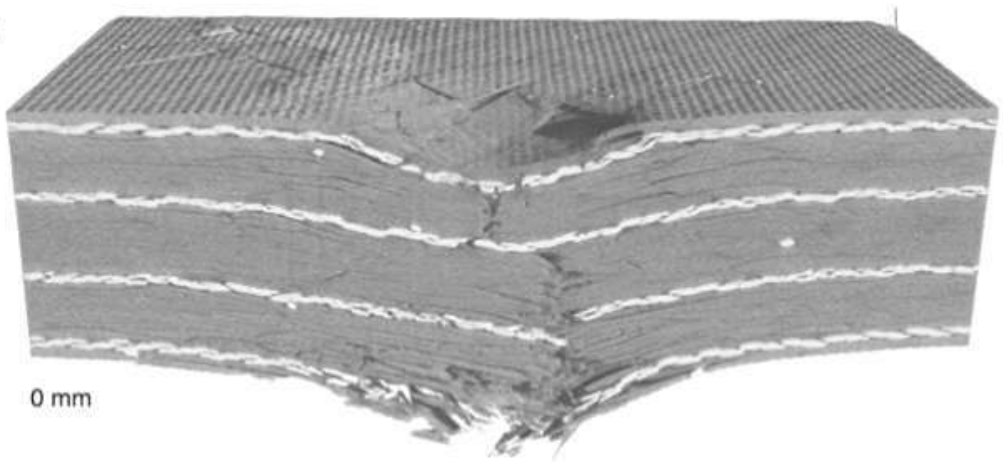

(b)

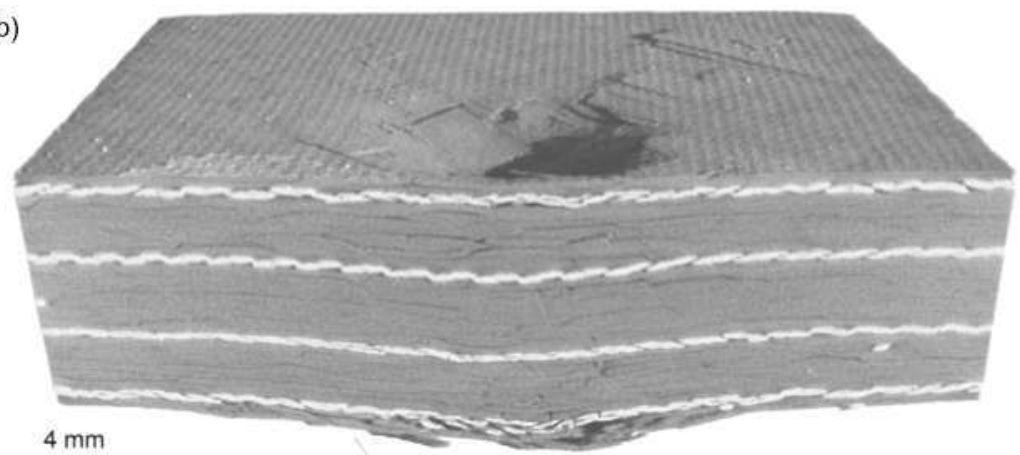

Figure 11. X-ray tomography sections of the H-22 (11) hybrid-epoxy laminate subjected to out-of-plane lowvelocity impact with $92 \mathrm{~J}$ : (a) under the impact axis and (b) $4 \mathrm{~mm}$ from the impact axis. The laminate thickness was $7.2 \mathrm{~mm}$. 
the presence of more glass fiber layers has helped to accumulate the nonlinear deformations without leading to intraply cracking. Nevertheless, it should be noted that these differences only led to marginal improvements in the maximum load and energy dissipated by the laminate.

\section{CONCLUSIONS}

The behavior of woven carbon-epoxy laminates hybridized with $\$ 2$ glass fibers was studied under low-velocity impact. Composite laminates with different thicknesses and volume fractions of $\mathrm{S} 2$ glass fibers (in the range 0-21 vol.\%) were manufactured by RTM and tested in a dropweight tower with kinetic energies from 30 to $245 \mathrm{~J}$ to obtain fully penetrated and nonpenetrated specimens. The results of the mechanical tests (in term of the maximum load-bearing capacity and the energy dissipated during impact) were analyzed in the light of the dominant deformation and fracture micromechanisms provided by $\mathrm{X}$-ray microtomography, and led to the following conclusions:

- The main deformation and damage micromechanisms were independent of the presence of glass fibers. The maximum load carried by the composite was controlled by the tensile fracture of the bottom carbon ply of the laminate subjected to bending (and it was proportional to $t^{2}$ ). In addition, intraply fracture by crushing below the tup was also initiated in the top plies. Intraply cracks formed in the top and bottom plies propagated through the lamina until they were deflected at the interply interface. Delamination progressed until interply cracks were deflected by matrix cracking into upper or lower plies. The final damage zone presented a conical shape and the overall energy dissipated by each material scaled with $e^{2}$, the volume of damaged material.

- Hybridization with S2 glass fibers increased the maximum load under impact (by approximately $10 \%$ ) and the energy dissipated (by approximately $25 \%$ for $21 \mathrm{vol} . \%$ of glass fibers). Improvements in both properties (particularly in the energy dissipated) were maintained even if the performance was compared in terms of specific properties (per unit of areal density).

- Improvements in the behavior under impact by hybridization were due to the higher strain-to-fracture of the $\$ 2$ glass fiber plies located near the top and bottom laminate surfaces. These plies were able to sustain higher deformations before fracture and hindered the propagation of damage to the inner plies from the broken plies on the bottom and top surfaces, increasing the maximum load-bearing capability of the composite. In addition, the presence of $\mathrm{S} 2$ glass fibers helped to sustain higher deformations before laminate fracture by the percolation of a through-thickness crack, significantly improving the energy dissipated under impact. Most of the benefits of the S2 glass fiber could be attributed to the plies located near the laminate surfaces. The presence of inner plies provided more limited improvements, particularly in terms of specific properties.

\section{ACKNOWLEDGMENTS}

This investigation was supported by Airbus Spain. Financial support from the Comunidad de Madrid under program ESTRUMAT-CM (S-2009/MAT-1585) is also gratefully acknowledged. The authors want to express their recognition to the assistance of Ms. N. Sola with the mechanical tests. 


\section{REFERENCES}

1. Cantwell. W.J. and Morton, J. (1991). The Impact Resistance of Composite Materials A Review, Composites, 22: 347-362.

2. Abrate, S. (1998). Impact on Composite Structures, Cambridge University Press, Cambridge.

3. Reid. S.R. and Zlou. G. (eds) (2000). Impact Behavior of Fibre-reinforced Materials and Structures, Woodhead Publishing Limited, Cambridge.

4. Bartus, S.D. and Vaidya, U.K. (2007). A Review: Impact Damage of Composite Materials, Journal of Adranced Materials, 39(3): 3-21.

5. Cantwell, W.J. and Morton, J. (1985). Detection of Impact Damage in CFRP Laminates, Composite Structures, 3: 24l-257.

6. Schoeppner, G.A. and Abrate, S. (2000). Delamination Threshold Loads for Low Velocity Impact on Composite Laminates. Composites: Part A, 31: 903-915.

7. Gellert, E.P., Cimpoeru. S.J. and Woodward. R.L. (2000). A Study of the Effect of Target Thickness on the Ballistic Perforation of Glass-fibre-reinforced Plastic Composites. International Journal of Impact Engineering, 24: 445-456.

8. Shyr, T.W. and Pan, Y.H. (2003). Impact Resistance and Damage Characteristics of Composite Laminates, Composite Structures, 62: 193-203.

9. Hosur, M.V., Vaidya, U.K. Ulven, C. and Jeelani, S. (2003). Performance of Stitched/ Unstitched Woven Carbon/Epoxy Composites Under High Velocity Impact Loading. Composite Structures, 61: 89-102.

10. Nemes, J.A.. Eskandari, H. and Rakitch, L. (1998). Effect of Laminate Parameters on Penetration of Graphite/Epoxy Composites, Intenational Joumal of Impact Engineering. 21: $97-112$.

11. Lopes, C.S., Seresta, O., Coquet, Y., Gürdal, Z., Camanho, P.P. and Thuis, B. (2009). Low-velocity Impact Damage on Dispersed Stacking Sequence Laminates. Part I: Experiments. Composite Science Technology, 69: 926-936.

12. Jang, B.Z., Chen. L.C., Hwang. L.R., Hawkes, J.E. and Zee, R.H. (1990). The Response of Fibrous Composites to Impact Loading. Polymer Composites, 11: 144-157.

13. Thanomsilp. C. and Hogg. P.J. (2003). Penetration Impact Resistance of Hybrid Composites Based on Commingled Yarn Fabrics, Composite Science Technology, 63: $467-482$.

14. Naik, N.K., Ramsimha, R., Arya, H., Prabhu, S.V. and Shamarao, N. (2001). Impact Response and Damage Tolerance Characteristics of Glass-Carbon/Epoxy Hybrid Composite Plates. Composites: Part B, 32: 565-574.

15. Hosur, M.V., Adbullah, M. and Jeelani, S. (2005). Studies of the Low-velocity Impact Response of Woven Hybrid Composites, Composite Structures, 67: 253-262.

16. Sevkat. E., Liaw, B., Delate, F. and Raju, B.B. (2009). Drop-weight Impact of Plain Woven Hybrid Glass-Graphite/Toughened Epoxy Composites, Composites: Part A, 40: $1090-1110$.

17. Kim, J.K. (2000). Recent Developments in Impact Damage Assessment of Fibre Composites, In: Reid. S.R. and Zhou, G. (eds). Impact Behaviour of Fibre-reinforced Composite Materials and Structures, pp. 33-74. Woodehead Publishing Limited, Cambridge.

18. Lavoie. J.A. and Adolfson. E. (2001). Stitch Cracks in Constraint Plies Adjacent to a Cracked Ply, Journal of Composite Materials, 35: 2077-2097.

19. Johnson, P. and Chang, F.K. (2001). Characterization of Matrix Crack-induced Laminate Failure - Part I: Experiments, Journal of Composite Materials, 35: 2009-2035.

20. Symons, D.D. (2000). Characterization of Indentation Damage in 0/90 Lay-up T300/914 CFRP, Composite Science Technology, 60: 391-401.

21. Schilling, P.J., Karedla, B.P.R., Tatiparthi, A.K., Verges, M.A. and Herrrington, P.D. (2005). X-ray Computed Microtomography of Internal Damage in Fiber Reinforced Polymer Matrix Composites. Composite Science Technology, 65: 2071-2078. 
22. Bayraktar, E., Antolonovich. S. and Bathias, C. (2006). Multiscale Study of the Fatigue Behavior of Composite Materials by X-Rays Computed Tomography, International Journal of Fatigue, 26: 1322-1333.

23. Wright, P., Fu. X., Sinclair, I. and Spearing, M. (2008). Ultra High Resolution Computed Tomography of Damage in Notched Carbon Fibre-Epoxy Composites, Joumal of Composite Materials, 42: 1993-2002.

24. Lopes, C.S., Camanho. P.P.. Gürdal, Z., Maimi. P. and González, E.V. (2009). Low-velocity Impact Damage on Dispersed Stacking Sequence Laminates. Part II: Numerical Simulations, Composite Science Technology, 69: 937-947. 